\title{
Biogenesis of Mitochondrial Membranes \\ in Neurospora crassa during Cellular Differentiation: Changes in Oxidative Phosphorylation and Synthesis of Mitochondrial Phospholipids
}

\author{
By D. P. BECK* AND J. W. GREENAWALT $\dagger$ \\ Department of Physiological Chemistry, \\ Johns Hopkins University School of Medicine, \\ Baltimore, Maryland 21205, U.S.A.
}

(Received 5 May 1975; revised 23 July 1975)

\section{SUMMARY}

Changes in the capacity of mitochondria to carry out oxidative phosphorylation and in the rate of synthesis and incorporation of phospholipids into mitochondria were measured during the germination of conidiospores of Neurospora crassa. The competence of isolated mitochondria to carry out coupled respiration was very low during the first $3 \mathrm{~h}$ growth, but it increased rapidly, reaching maximal levels at 5 to $6 \mathrm{~h}$ growth. Changes in mitochondrial function were the same in cells grown in $2 \%$ sucrose- or $15 \%$ glucose-supplemented medium. The rate of synthesis of mitochondrial phospholipids was very low during the first $2 \mathrm{~h}$ growth and increased to maximal levels between 3 and $5 \mathrm{~h}$. The rate of synthesis of mitochondrial phospholipids was approximately three times higher in cells grown in $15 \%$ glucose than in those grown in $2 \%$ sucrose. The maximal rate of synthesis of mitochondrial phospholipids occurred during spore germination and preceded attainment of full competence for oxidative phosphorylation. The lipid-rich condition of the mitochondria resulting from the high rate of synthesis of phospholipids in glucose-grown cells is postulated to be related to the whorled inclusions observed in thin sections of Neurospora cells.

\section{INTRODUCTION}

Since the germination and growth of conidiospores of Neurospora crassa are oxygendependent processes, it appears likely that the dedifferentiation and redifferentiation of these cells from spores into growing hyphae must be dependent upon mitochondrial function. The levels of several mitochondrial enzyme activities are higher during germination than they are in the conidia (Zalokar, 1959; Weiss, 1965). Early studies in this laboratory showed that the increases in mitochondrial respiration occurred during the period of spore germination (Hall \& Greenawalt, 1964, 1967). More recently it was found that the rate of mitochondrial protein synthesis also reached maximal levels during this phase of growth (Greenawalt, Beck \& Hawley, 197I). Since these proteins are incorporated primarily into the inner mitochondrial membrane (Kellerman et al. 197I), the redifferentiation of Neurospora conidiospores into vegetative hyphae must be dependent upon the development of functional mitochondrial membranes. Therefore, it was of interest to see if the

\footnotetext{
* Present address: Maryland Psychiatric Research Center, Baltimore, Maryland 21228, U.S.A.

+ Present address: Department of Biochemistry, University of Tennessee, Knoxville, Tennessee 37916 , U.S.A.
} 
increase in mitochondrial protein synthesis might be accompanied by modulation of the synthesis of mitochondrial phospholipids. In the preceding paper (Beck \& Greenawalt, 1976), ultrastructural studies of redifferentiating conidia showed that lipophilic, whorled inclusions appeared within the mitochondria during the germination period. The frequency of appearance of these inclusions was dependent on the time of growth and carbohydrate supplement in the medium. Experiments were undertaken to determine if these inclusions might be correlated with changes in the lipid composition of Neurospora mitochondria at different stages of growth as well as with the development of mitochondrial function.

This paper describes a kinetic examination of the increase in mitochondrial competence for oxidative phosphorylation, and a study of the synthesis of mitochondrial lipids during germination and early exponential growth of Neurospora cells in sucrose- and glucosesupplemented medium.

\section{METHODS}

Neurospora cultures and electron microscopy. Neurospora crassa SY7A was grown as described (Beck \& Greenawalt, 1976).

The mitochondrial fractions (see below) were prepared for electron microscopy by fixation with glutaraldehyde and osmium tetroxide, dehydrated and embedded, and poststained as described (Beck \& Greenawalt, 1976).

Mitochondrial isolation and assay. Mitochondria were prepared from Neurospora cells by grinding with glass beads in a Mini-Mill (Gifford Wood Co., Hudson, New York, U.S.A.). The procedure was essentially that of Hall \& Greenawalt (1967) except that the bovine serum albumin (BSA) content of the isolation medium was increased to $0.25 \%$ and the isolation procedure was shortened considerably. A mitochondrial fraction was obtained by differential centrifugation and was then further purified by centrifugation on a $30 \%(w / v)$ solution of the methyl glucamine salt of Renographic acid (3,5-diacetylamino-2,4,6-tri-iodobenzoate) which has a density of approximately $\mathrm{I} \cdot \mathrm{I} 6 \mathrm{~g} / \mathrm{cm}^{3}$. Renografic acid was a gift from Squibb Institute for Medical Research, New Brunswick, New Jersey, U.S.A. Up to I $\mathrm{ml}(60 \mathrm{mg}$ protein $/ \mathrm{ml})$ of mitochondrial suspension was layered on $15 \mathrm{ml}$ of $30 \%(\mathrm{w} / \mathrm{v})$ Renografin $\mathrm{pH} 7.4$ in a $50 \mathrm{ml}$ tube, and centrifuged in a fixed angle rotor at $7700 \mathrm{~g}$ for $10 \mathrm{~min}$. The mitochondrial fraction remained at the top of the Renografin while most debris sedimented to the bottom of the tube. The mitochondrial band was carefully collected and washed in at least 10 vol. of preparation medium.

Mitochondrial respiration was measured at $25^{\circ} \mathrm{C}$ with a Clark oxygen electrode (Kielley, 1963) in a closed glass chamber (Gilson Medical Electronics, Middleton, Wisconsin, U.S.A.) equipped with a magnetic stirrer. The reaction medium was $0.44 \mathrm{M}$-mannitol in $10 \mathrm{mM}-$ sodium phosphate buffer $\mathrm{pH} 7 \cdot 2$. The oxygen solubility in this medium was $420 \mathrm{n}$-atom $/ \mathrm{ml}$ (Balcavage \& Mattoon, 1968). Respiratory control and ADP:O ratios were calculated from the polarographic tracings by the method of Chance \& Williams (1955).

Mitochondrial protein was determined by the method of Murphy \& Kies (1960). Oligomycin and antimycin A were obtained from Sigma, and were dissolved in $100 \%$ redistilled methanol.

Lipid extraction and analysis. Lipids were extracted from whole cells and isolated mitochondria of Neurospora by the procedure of Folch, Lees \& Sloane-Stanley (1957). The modification of Letters (1967) was used with whole cells to improve extraction. Lipids were separated and analysed by thin-layer chromatography in the two-dimensional system of Nichols \& James (1964). Individual lipids were identified by specific spray reagents (Skipski \& Barclay, 1969) and by co-chromatography with standards. Samples of total 


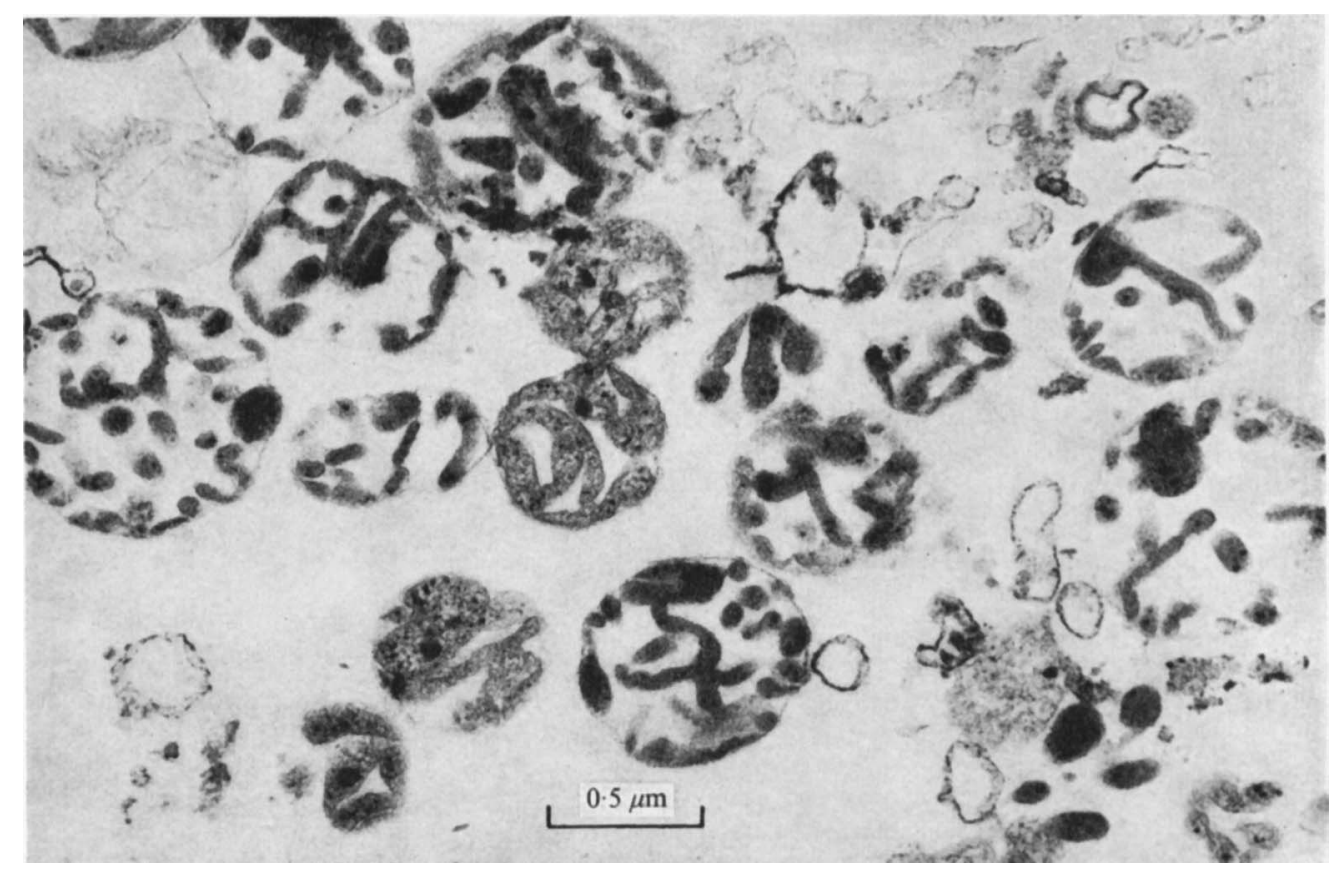

Fig. 1. Neurospora mitochondria after purification. Thin section of mitochondria prepared from cells grown for $18 \mathrm{~h}$ in medium containing $2 \%(\mathrm{w} / \mathrm{v})$ sucrose and fixed for electron microscopy after purification on Renografin as described in Methods.

lipid or lipid spots from chromatograms were analysed for phosphate by the Bartlett (1959) procedure.

Synthesis of Neurospora lipids was measured by pulse-labelling with [U-14 C]glucose ( $10^{5}$ c.p.m. $\left./ \mu \mathrm{mol}\right)$ or ${ }^{32} \mathrm{P}^{3} \mathrm{H}_{3} \mathrm{PO}_{4}\left(2 \cdot 2 \times 10^{5}\right.$ c.p.m. $\left./ \mu \mathrm{mol}\right)$, both from New England Nuclear, Boston, Massachusetts, U.S.A. High-specific-activity labelled precursor was added to yield the above specific activities in the culture medium $30 \mathrm{~min}$ before the indicated sampling time. Following extraction and separation, labelled lipids were counted in a Beckman LS-1 50 liquid scintillation counter. The scintillation fluid was $0.01 \%$ I,4-bis $\left[2^{\prime}\right.$-(5-phenyloxazolyl)]benzene and $0.4 \%$ 2,5-diphenyloxazole in toluene. The toluene solution was diluted $(1250 \mathrm{ml})$ up to $2: 1$ with absolute ethanol for measuring radioactivity in a growth medium containing large amounts of sugar.

\section{RESULTS}

\section{Changes in mitochondrial function during germination}

Mitochondria were isolated from differentiating cells at various times throughout the germination and exponential periods of growth, i.e. during the first $8 \mathrm{~h}$ after inoculation (Beck \& Greenawalt, 1976). The mitochondrial fraction was enriched and contamination largely eliminated by centrifugation on Renografin as described in Methods. The mitochondrial fraction obtained by differential centrifugation contained cell wall fragments and membranous debris; most of this contamination was sedimented from the top of the Renografin solution, leaving a clean mitochondrial fraction (Fig. I). Mitochondria from cells of various ages grown in either $2 \%(w / v)$ sucrose or $15 \%(w / v)$ glucose were very similar to the one shown in Fig. I. Despite much effort to find them in thin sections, no 


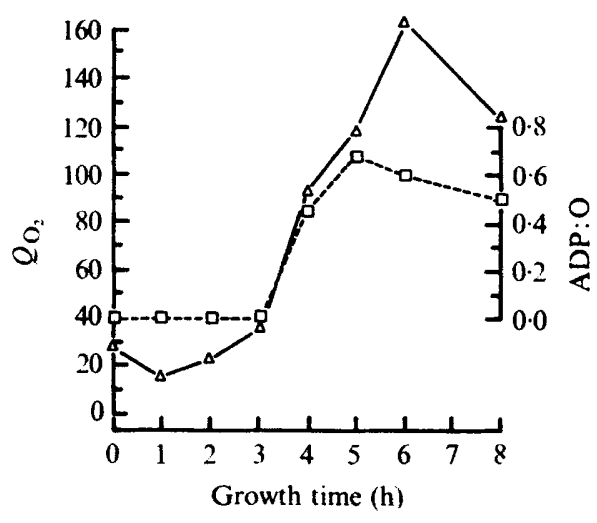

Fig. 2

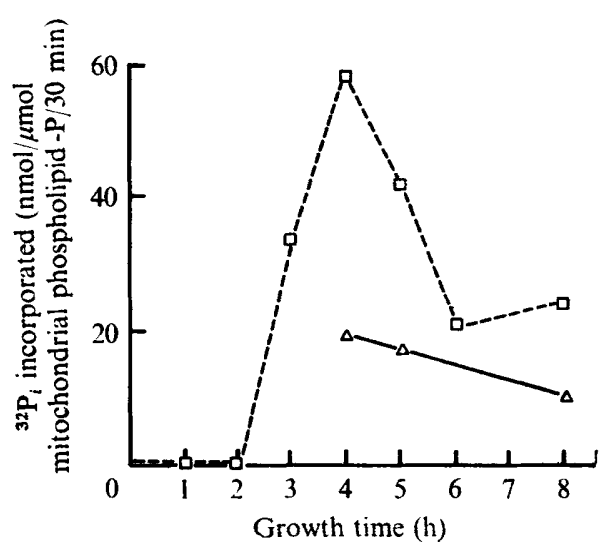

Fig. 3

Fig. 2. Mitochondrial respiration and oxidative phosphorylation. Mitochondrial respiration was measured polarographically at $25^{\circ} \mathrm{C}$ in a reaction volume of $x .5 \mathrm{ml}$ as described in Methods.

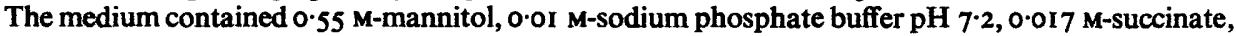
and $\mathrm{I} \cdot 5$ to $3.0 \mathrm{mg}$ mitochondrial protein. ADP:O ratios ( $\square$ ) were measured after the addition of $67 \mu \mathrm{M}$-ADP. The rate of respiration, $Q_{0_{2}}(\triangle)$ is expressed as $\mathrm{n}$-atom/min/mg mitochondrial protein.

Fig. 3. Synthesis of total mitochondrial phospholipids during cellular differentiation in sucroseor glucose-supplemented medium. Cells were pulsed at various times for $30 \mathrm{~min}$ with $\left[{ }^{32} \mathrm{P}_{\mathrm{l}}\right] \mathrm{H}_{3} \mathrm{PO}_{4}$ (about $2.2 \times 10^{5}$ c.p.m. $/ \mu \mathrm{mol}$ ) during growth in $(\triangle) 2 \%$ sucrose or $(\square) 15 \%$ glucose (about $10^{5}$ c.p.m. $(\mu \mathrm{mol})$. Lipids were extracted from purified mitochondria and analysed for radioactivity by liquid scintillation counting.

membranous inclusions (such as those described in Beck \& Greenawalt, 1976) were observed in the isolated mitochondria.

Respiration and the degree of coupling of oxidation to phosphorylation were measured in mitochondria isolated during the germination and early exponential periods of growth. They were similar in mitochondria from cells grown in $15 \%$ glucose (Fig. 2) and in $2 \%$ sucrose. During the first $3 \mathrm{~h}$ growth, rates of respiration were low. Between 3 and $6 \mathrm{~h}$ after inoculation, an almost linear increase in respiration occurred, and the rate of respiration $\left(Q_{\mathrm{O}_{2}}\right)$ increased approximately 5 -fold. Accompanying this increase in respiration at $3 \mathrm{~h}$ growth was a rapid and marked increase in the degree of coupling of oxidation to phosphorylation as indicated by the rise in the ADP:O ratio. Similar results were obtained for the oxidation of several other substrates, including pyruvate-malate, citrate, $\alpha$-ketoglutarate and ethanol, by mitochondria. From the data presented (Beck \& Greenawalt, 1976), it is clear that dedifferentiative and redifferentiative processes are completed by the time maximal respiratory rates are achieved (at 5 to $6 \mathrm{~h}$ growth), and that significant increases in respiratory rate do not occur until 50 to $60 \%$ of the cells have germinated (at about $3.5 \mathrm{~h}$ growth).

Succinate oxidation by mitochondria isolated from cells germinated for more than $3 \mathrm{~h}$ was inhibited by low concentrations $(2 \mu \mathrm{g} / \mathrm{mg}$ protein) of antimycin $\mathrm{A}$, an inhibitor of electron transport. In the presence of oligomycin, an inhibitor of coupled oxidative phosphorylation, maximal inhibition of state-3 respiration was achieved only by high concentrations of antibiotic (I I $\mu \mathrm{g} / \mathrm{mg}$ protein). This concentration is similar to that required for maximal inhibition of state-3 respiration in yeast mitochondria (Balcavage \& Mattoon, 1968), but Io-fold higher than that needed for inhibition with rat liver mitochondria (Huijing \& Slater, 196I). 
Table I. Phospholipid composition of Neurospora mitochondria

\begin{tabular}{|c|c|c|c|c|c|c|c|}
\hline \multirow{3}{*}{$\begin{array}{l}\text { Growth supplement } \\
\text { Time of growth (h) }\end{array}$} & \multirow{3}{*}{$\begin{array}{l}\cdots \\
0\end{array}$} & \multirow[b]{2}{*}{$\cdots$} & \multicolumn{5}{|c|}{ Recovered phosphate $(\%)$} \\
\hline & & & \multicolumn{2}{|c|}{ Sucrose $(2 \%)$} & \multicolumn{3}{|c|}{ Glucose (15\%) } \\
\hline & & 4 & 5 & 8 & 4 & 5 & 8 \\
\hline Pl & I & I & I & I & 6 & I & 0 \\
\hline PS & II & 6 & 9 & 6 & 2 I & 24 & 19 \\
\hline PC & 12 & 8 & II & 8 & 18 & 27 & 31 \\
\hline PA & I & 4 & 2 & 3 & $\mathbf{I}$ & 2 & 4 \\
\hline PE & 38 & 39 & 4I & 40 & 25 & 23 & 21 \\
\hline DPG & 34 & 43 & 35 & 42 & 14 & 22 & 22 \\
\hline
\end{tabular}

PI, phosphatidylinositol; PS, phosphatidylserine; PC, phosphatidylcholine; PA, phosphatidic acid; PE, phosphatidylethanolamine; DPG, diphosphatidylglycerol.

Table 2. PC and PE content in cellular lipids of Neurospora

\begin{tabular}{cccc}
$\begin{array}{c}\text { Growth } \\
\text { time } \\
\text { (h) }\end{array}$ & \multicolumn{3}{c}{ Percentage of total phosphate recovered in: } \\
\cline { 2 - 4 } 0 & PC & PE & PC+PE \\
2 & 53 & 29 & 82 \\
4 & 56 & 27 & 83 \\
6 & 49 & 31 & 80 \\
8 & 43 & 40 & 83 \\
& 43 & 38 & 81
\end{tabular}

For abbreviations, see Table $\mathbf{I}$.

\section{Mitochondrial lipid composition and synthesis}

Mitochondria were isolated from cells grown for various times in medium supplemented with $2 \%$ sucrose or $15 \%$ glucose and their phospholipid composition and synthesis measured. Mitochondria from conidia have a lipid:protein ratio of about 0.12 and a phospholipid: lipid ratio of about $0 \cdot 2$. Thin-layer chromatographic analysis of mitochondrial lipids shows a number of phospholipids (Table 1), a large sterol fraction, and only small amounts of free fatty acids. There were several significant differences between the mitochondrial phospholipid compositions of sucrose- and glucose-grown cells. By $4 \mathrm{~h}$, mitochondria from cells grown in $15 \%$ glucose contained a significantly greater proportion of phosphatidylserine (PS) and phosphatidylcholine (PC) and significantly smaller proportions of phosphatidylethanolamine (PE) and diphosphatidylglycerol (cardiolipin, DPG) than do mitochondria from $2 \%$ sucrose-grown cells. There was an increase in the proportion of $\mathrm{PC}$ and a reciprocal decrease in the content of PE in the mitochondrial lipid of cells grown in $15 \%$ glucose. Similar changes in the lipids of mitochondria from cells grown in $2 \%$ sucrose were not apparent. This change in the proportion of PC and PE in mitochondrial lipids contrasted with the changes in the proportions of these lipids in the whole cell lipid extract, where the relative amounts of PC decreased and of PE increased with time, while the total amount of these two lipids remained essentially constant (Table 2).

The rate of synthesis of phospholipids of mitochondria was measured by pulse-labelling cells growing in sucrose- or glucose-supplemented medium with $\left[{ }^{32} \mathrm{P}_{3} \mathrm{H}_{3} \mathrm{PO}_{4}\right.$. Since it is likely that turnover was low in these rapidly growing and expanding cells, especially during the course of a half-hour pulse, we have assumed that labelling of phospholipid is 
Table 3. ${ }^{32} P$-labelling of mitochondrial lipids

\begin{tabular}{|c|c|c|c|c|c|c|c|}
\hline \multirow{3}{*}{$\begin{array}{l}\text { Growth supplement } \\
\text { Growth time (h) }\end{array}$} & & \multicolumn{6}{|c|}{${ }^{32} \mathrm{P}$ incorporated (nmol $/ \mu \mathrm{mol}$ phospholipid-P/30 min) } \\
\hline & $\ldots$ & \multicolumn{2}{|c|}{ Sucrose $(2 \%)$} & \multicolumn{4}{|c|}{ Glucose $(15 \%)$} \\
\hline & 4 & 5 & 8 & 2 & 4 & 5 & 8 \\
\hline PI & 0.0 & 0.0 & 0.0 & 0.0 & $I \cdot 4$ & 0.1 & 0.0 \\
\hline PS & 0.2 & 0.3 & $0 \cdot I$ & 0.0 & $4 \cdot 2$ & $I \cdot 2$ & 0.1 \\
\hline PC & $4 \cdot 2$ & $2 \cdot 9$ & $I \cdot 6$ & I. 5 & $18 \cdot 0$ & $5 \cdot 5$ & 0.9 \\
\hline PA & 0.9 & 0.8 & 0.2 & 0.0 & $2 \cdot 7$ & 0.5 & 0.3 \\
\hline PE & $1 \cdot 8$ & $2 \cdot I$ & $I \cdot 4$ & $1 \cdot 5$ & $4 \cdot 1$ & $1 \cdot 6$ & 0.3 \\
\hline DPG & $5 \cdot 3$ & $4 \cdot 4$ & 3.0 & $2 \cdot 2$ & $8 \cdot 4$ & $2 \cdot 2$ & 0.5 \\
\hline
\end{tabular}

For abbreviations, see Table 1 .

representative of phospholipid synthesis. Very little label was detected in the mitochondrial lipid of glucose-grown cells less than $2 \mathrm{~h}$ after inoculation when the cells were still in a lag phase (Beck \& Greenawalt, 1976), but the rate of incorporation of ${ }^{32} P_{i}$ increased dramatically for the next $2 \mathrm{~h}$, reaching a maximal rate at $4 \mathrm{~h}$ growth (Fig. 3). The rate of labelling of the mitochondrial phospholipids decreased after $4 \mathrm{~h}$ in glucose-grown cells. The rate of ${ }^{32} \mathrm{P}_{\mathrm{i}}$ incorporation into the phospholipids of mitochondria of sucrose-grown cells also decreased after $4 \mathrm{~h}$, indicating that in these cells the maximum is at $4 \mathrm{~h}$ or before. The rate of synthesis of phospholipids of mitochondria from sucrose-grown cells was only $30 \%$ of the rate of those from glucose-grown cells at $4 \mathrm{~h}$ growth. These results on labelling mitochondrial phospholipids in glucose-grown cells have been confirmed by the use of $\left[{ }^{14} \mathrm{C}\right]$ glucose in similar pulse-labelling experiments. Therefore, it appears that incorporation of radioactivity represents synthesis of lipids rather than exchange of label.

Chromatographic analysis of the ${ }^{32} \mathrm{P}$-labelled lipids indicated that there are significant differences between the synthesis of individual phospholipids in sucrose- and glucose-grown cells (Table 3). Little incorporation was observed at $2 \mathrm{~h}$ growth in glucose. By $4 \mathrm{~h},{ }^{32} \mathrm{P}_{1}$ incorporation appeared to reach maximal levels for most phospholipids in sucrose- and glucose-grown cells, but the maximal levels were markedly higher in glucose-grown cells.

\section{DISCUSSION}

Neurospora mitochondrial lipids were synthesized at maximal rates during the period of 3 to $5 \mathrm{~h}$ growth. The rate of respiration and the degree of coupling of oxidative phosphorylation in Neurospora mitochondria increased markedly and reach maximal values at 5 to $6 \mathrm{~h}$ growth. The initiation of these increases correlated well with the onset of redifferentiation and entrance into exponential growth and they show that the time between 3 and $6 \mathrm{~h}$ growth of Neurospora crassa is a period of intense cellular activity. This germination period includes morphological changes (Beck \& Greenawalt, 1976), increases in mitochondrial enzyme complement (Hall \& Greenawalt, 1964; Mannino, 1973), synthesis of mitochondrial and cellular nucleic acids (Mannino, 1973), and attainment of maximal rates of cellular respiration, cellular and mitochondrial protein synthesis (Hawley \& Greenawalt, 1975), and cellular phospholipid synthesis (Greenawalt et al. 1971).

We have considered the possibility that the changes observed in mitochondrial activities may reflect alterations in the mitochondria during isolation, but the changes in rates of protein synthesis have been studied both in isolated mitochondria and in intact cells (Hawley \& Greenawalt, 1975). Mitochondria were isolated at all sampling times by the 
same procedure, which was originally designed to provide for isolation from the conidia which are difficult to disrupt. Thus, any possible damage would be expected to be greater to the mitochondria from hyphae rather than to those from the conidia. Also, mitochondria were routinely purified by centrifugation on Renografin and monitored ultrastructurally. No evidence of selective, time-dependent damage was observed. In addition, damage to the mitochondria during isolation might be expected to decrease the degree of coupling but not to decrease the $Q_{\mathrm{O}_{2}}$. If damage were a major factor, the $Q_{\mathrm{O}_{2}}$ would be expected to be increased. At early times we find both low $Q_{o_{2}}$ and respiratory control. Therefore, all the available evidence indicates that selective, time-dependent damage does not account for the results we have obtained. Finally, the ADP:O ratios with Neurospora mitochondria were relatively low compared with mammalian mitochondria. This may be due to the large amount of cyanide-insensitive respiration in Neurospora mitochondria (Lambowitz \& Slayman, 1971).

The results described for labelling of the mitochondrial phospholipids could be due to contamination of the mitochondrial fraction by other cellular membranes. Although a small amount of debris remained in the mitochondrial fraction, as assayed ultrastructurally, even after purification on Renografin, the specific changes in the content of PE and PC of mitochondrial versus cellular lipids (Tables $I$ and 2) showed that the actual mass of the contaminating material must have been small. Significant contamination of the mitochondrial lipids by cytoplasmic lipids would not allow detection of the inverse changes of PE and PC demonstrated in Table I.

The synthesis of mitochondrial lipids, normal components of the mitochondrial membranes, preceded full development of mitochondrial membrane function. Since a number of studies have described the lipid requirement for activity of several mitochondrial enzymes (Gotterer, 1967, Fleischer, Fleischer \& Stoeckenius, 1967; Green et al. 1967; Castelli, Barbaresi \& Bertoli, 1969; Sartorelli et al. 1967; Awasthi et al. 1971), we suggest that the synthesis of mitochondrial lipids is an indicator of the synthesis of functional mitochondrial membrane. It has been found, for example, that the DPG content of the mitochondrial membranes is closely correlated with the mitochondrial function during derepression of Saccharomyces cerevisiae (Jakovic et al. 197I). Since DPG is associated extensively with the mitochondria (Fleischer et al. 1967; Getz et al. 1968) and especially with the inner membrane (Parsons et al. 1967; McMurray \& Dawson, 1969), its synthesis could be expected to parallel the increase in mitochondrial function in Neurospora. The similarities in respiration and in coupling of oxidative phosphorylation in mitochondria from sucrose- and glucose-grown cells, and the relative similarities of the rates of labelling of DPG under these growth conditions support this hypothesis. The rates of synthesis of the other mitochondrial phospholipids also change during germination and the magnitude of these changes is dependent on the carbohydrate supplement in the growth medium. In spite of the differences in the rates of phospholipid synthesis, changes in the number of mitochondria per cell (Beck, 1971), in respiration, in the degree of coupling of oxidative phosphorylation, and in growth (increase in dry weight) (Beck \& Greenawalt, 1976) are similar in $2 \%$ sucrose- and in $15 \%$ glucose-supplemented media. These facts indicate that normal differentiation processes occur in both types of media, but that certain biochemical pathways are enhanced by high concentration of glucose.

Lipid-containing whorls occur in mitochondria during the germination period of Neurospora (Beck \& Greenawalt, 1976). Although it is uncertain whether the ultrastructural appearance represented the native state of the mitochondrial components, the dependence of their numbers on time of growth and on carbohydrate supplement indicated 
that their presence reflected real differences in the cell and in the mitochondria. That there is a relationship between the appearance of mitochondrial whorls and the rate of phospholipid synthesis during redifferentiation is supported (i) by the correlation between the higher incorporation of ${ }^{32} \mathrm{P}_{\mathrm{i}}$ into mitochondrial lipids and the higher numbers of mitochondrial inclusions in glucose-grown cells than in sucrose-grown cells, and (ii) by the correlation between the time of maximal rate of labelling of mitochondrial phospholipids and maximal numbers of mitochondrial whorls. Further experiments are necessary to determine the precise nature and possible role of these components in the development of mitochondrial functions.

This research was supported by research grants GMI2I25 from the National Institutes of Health and GB31098 from the National Science Foundation to J.W.G., and by USPHS training grant GMooI84 to the Department of Physiological Chemistry, Johns Hopkins University School of Medicine. We are grateful to Dr Jeanne C. Beck for critically reading the manuscript and to $\mathrm{Mr}$ G. L. Decker and $\mathrm{Mr}$ R. A. Garrett for expert technical assistance.

\section{REFERENCES}

Awasthi, Y., Chuang, T. F., Keenan, T. W. \& Crane, F. L. (1971). Tightly bound cardiolipin in cytochrome oxidase. Biochimica et biophysica acta 226, 42-52.

Balcavage, W. X. \& Mattoon, J. R. (1968). Properties of Saccharomyces cerevisiae mitochondria prepared by a mechanical method. Biochimica et biophysica acta 153, 521-530.

BARTLETT, G. (1959). Human red cell glycolytic intermediates. Journal of Biological Chemistry 234, 449458.

BECK, D. P. (1971). Morphogenesis in Neurospora crassa. Cytological and biochemical aspects of mitochondrial development. Ph.D. Dissertation, John Hopkins University.

BeCK, D. P. \& Greenawalt, J. W. (1976). Biogenesis of mitochondrial membranes in Neurospora crassa during cellular differentiation: ultrastructural changes accompanying differentiation. Journal of General Microbiology. 92, 97-1 10.

Castelll, A., Barbaresi, G. \& Bertoli, E. I. (1969). Studies on the lipids of $S$. cerevisiae during the growth phase. Italian Journal of Biochemistry 18, $91-99$.

Chance, B. \& Williams, G. (1955). Respiratory enzymes in oxidative phosphorylation. I. Kinetics of oxygen utilization. Journal of Biological Chemistry 217, 383-393.

Fleischer, S., Fleischer, B. \& Stoeckentus, W. (1967). Fine structure of lipid-depleted mitochondria. Journal of Cell Biology 32, 193-208.

Folch, J., Lees, M. \& Sloane-Stanley, G. H. (1957). A simple method for the isolation and purification of total lipids from animal tissues. Journal of Biological Chemistry 226, 497-509.

Getz, G., Bartley, W., LURIE, D. \& Notron, B. (I968). The phospholipids of various sheep organs, rat liver, and of their subcellular fractions. Biochimica et biophysica acta 152, 325-339.

GoTTERER, G. (1967). Rat liver D- $\beta$-hydroxybutyrate dehydrogenase. II. Lipid requirement. Biochemistry 6, $2147-2152$.

Green, D., Allman, D., Bachmann, E., Baum, H., Kopaczyk, K., Korman, E., Lipton, S., Mclennan, D., McConnell, D., Perdue, J., Rieske, J. \& Tzagoloff, A. (1967). Formation of membranes by repeating units. Archives of Biochemistry and Biophysics $119,312-335$.

Greenawalt, J. W., Beck, D. P. \& Hawley, E. S. (1971). Chemical and biochemical changes in mitochondria during morphogenetic development of Neurospora crassa. In Biochemistry and Biophysics of Mitochondrial Membranes, pp. 541-558. Edited by G. F. Azzone, E. Carafoli, A. L., Lehninger, E. Quagliarello and N. Siliprandi. New York: Academic Press.

Hall, D. O. \& Greenawalt, J.W. (I964). Oxidative phosphorylation by isolated mitochondria of Neurospora crassa. Biochemical and Biophysical Research Communications 17, 565-569.

Hall, D. O. \& GreenAWALT, J. W. (1967). The preparation and biochemical properties of mitochondria from Neurospora crassa. Journal of General Microbiology 48, 419-430.

Hawley, E. S. \& Greenawalt, J. W. (1975). Biogenesis of mitochondrial membranes in Neurospora crassa. Mitochondrial protein synthesis during conidial germination. European Journal of Biochemistry 54, 585-601.

Huting, F. \& Slater, E. C. (1961). The use of oligomycin as an inhibitor of oxidative phosphorylation. Journal of Biochemistry 49, 493-503.

Jakovcic, S., Getz, G. S., Rabinowitz, M., Jakob, H. \& SwiFt, H. (1971). Cardiolipin content of wild type and mutant yeasts in relation to mitochondrial function and development. Journal of Cell Biology 48, 490-502. 
Kellerman, G., Griffiths, D., Hansby, J., Lamb, A. \& LinNane, A. (1971). The protein synthetic capacity of yeast mitochondria and the role of the mitochondrial genome in the economy of the cell. In Autonomy and Biogenesis of Mitochondria and Chloroplasts, pp. 346-359. Edited by N. K. Boardman, A. W. Linnane and R. M. Smillie. Amsterdam: North-Holland.

Kielley, W. W. (1963). Preparation and assay of phosphorylating submitochondrial particles: sonicated mitochondria. Methods in Enzymology 6, 272-277.

LAmbowtrZ, A. M. \& Slayman, C. W. (197I). Cyanide-resistant respiration in Neurospora crassa. Journal of Bacteriology ro8, $1087-1096$.

LeTters, R. (1967). Phospholipids of yeast. In Aspects of Yeast Metabolism, pp. 303-320. Edited by A. Wills. Oxford: Blackwell Scientific.

MANNINO, R. J. (1973). Quantitative changes in mitochondrial nucleic acids associated with the development of conidiospores of Neurospora crassa. Ph.D. dissertation, Johns Hopkins University.

McMurray, W. \& DAwson, R. (1969). Phospholipid exchange reactions within the liver cell. Biochemical Journal I12, 91-108.

MuRPHY, J. B. \& KIES, M. W. (1960). Note on spectrophotometric determination of proteins in dilute solutions. Biochimica et biophysica acta 45, 382-384.

Nicholss, B. \& JAMEs, A. (1964). The lipids of plant storage tissue. Fette, Seifen, Anstrichmittel 66, 10031006.

Parsons, D., Williams, G., Thompson, W., Wilson, D. \& Chance, B. (1967). Improvements in the procedure for purification of mitochondrial outer and inner membrane. Comparison of the outer membrane with smooth endoplasmic reticulum. In Mitochondrial Structure and Compartmentation, pp. 29-70. Edited by E. Quagliariello, S. Papa, E. Slater and J. Tager. Bari: Adriatica Editrice.

Sartorelit, L., Galzigna, L., Rossi, C. \& Gibson, D. (1967). Influence of lecithin on the activity of the GTP-dependent acetyl CoA-synthetase. Biochemical and Biophysical Research Communications 26, 90-94.

SkIPSKI, V. \& BARCLAY, M. (1969). Thin-layer chromatography of lipids. Methods in Enzymology I4, $530-598$.

Weiss, B. (1965). An electron microscope and biochemical study of Neurospora crassa during development. Journal of General Microbiology 39, 85-94.

ZaloKar, M. (1959). Enzyme activity and cell differentiation in Neurospora. American Journal of Botany 46, 555-559. 